\title{
Comparing post-release cover and burrow use by differentially head-started Mojave desert tortoises in southern California
}

\author{
Pearson A. McGovern ${ }^{1,2}$, J. Mark Peaden ${ }^{3}$, Kurt A. Buhlmann ${ }^{1}$, Brian D. Todd ${ }^{4}$, \& Tracey D. Tuberville ${ }^{1 *}$ \\ ${ }^{1}$ Savannah River Ecology Laboratory, University of Georgia, PO Drawer E, Aiken, SC 29802, USA \\ ${ }^{2}$ Warnell School of Forestry and Natural Resources, University of Georgia, 180 E. Green Street, Athens, GA 30602, \\ USA \\ ${ }^{3}$ Department of Biology, Rogers State University, 1701 W. Will Rogers Boulevard, Claremore, OK 74017, USA \\ ${ }^{4}$ Department of Wildlife, Fish and Conservation Biology, University of California, Davis, One Shields Ave, Davis, CA \\ 95616, USA
}

DOI: https://doi.org/10.52201/CEJ18EEQD6739

\section{SUMMARY}

The effects of indoor rearing versus the conventional method of solely outdoor head-starting on post-release cover and burrow use of juvenile Mojave desert tortoises (Gopherus agassizii), a threatened endemic species, were investigated. We found that partially indoor-reared tortoises exhibited similar post-release behaviours when compared to both same-aged, but smaller, and similar-sized, but older outdoor-reared head-started tortoises, thus increasing the success and decreasing the costs of head-starting.

\section{BACKGROUND}

Active management techniques for conserving wildlife are gaining prominence as wildlife populations continue to decline (Tetzlaff et al. 2019). One such active management approach is head-starting, which is the rearing of offspring in captivity until they are of a size less prone to mortality after release (Burke 2015). While headstarting has been criticized in the past (Frazer 1992), its resurgence can be attributed to its use as a short-term recovery action embedded alongside broader conservation initiatives (Spencer et al. 2017). With this increased acceptance, head-starting is now being evaluated on a species-by-species basis, allowing managers to determine the best means of maximizing both program success and efficiency. The use of head-starting as a conservation measure has been successful in $60 \%$ of the 25 studies (from seven countries) assessed on the Conservation Evidence website (https://www.conservationevidence.com/actions/881); however, all studies focused on amphibians and varied in their sourcing of the animals and their husbandry practices.

The Mojave desert tortoise (Gopherus agassizii), listed as threatened under the US Endangered Species Act since 1990, is endemic to the Mojave and Colorado deserts of the Southwest USA (Averill-Murray et al. 2012). Due to drastic population declines from threats like habitat loss and degradation, road mortality, subsidized predators (predators whose populations are directly or indirectly inflated by human-altered resource availability), and nonnative vegetation (Averill-Murray et al. 2012), population augmentation efforts have been implemented to help

*corresponding author email address: tubervil@uga.edu recover this species. Initial projects focused on outdoor rearing that allowed individuals to grow in predator-proof enclosures in otherwise natural habitat. While survival was high in these enclosures, tortoise activity was seasonal and growth was slow, making the process time-consuming and thus increasing cost (Nagy et al. 2015a, Tuberville et al. 2019). Rearing head-started tortoises in this fashion until they reach a recommended release size of $\sim 100 \mathrm{~mm}$ midline carapace length (MCL; Nagy et al. 2015a) can take between $5-9$ years of outdoor captive rearing (Hazard et al. 2015, Nagy et al. 2015a). Since 2015, we have been evaluating the effectiveness of rearing tortoises indoors as a means of reducing the cost and time required to rear tortoises to sizes large enough for release (Daly et al. 2018, McGovern et al. 2020a).

Here we evaluate post-release behaviours of headstarted desert tortoises as they relate to our overall aim of determining whether there is a difference in survival between tortoises raised with or without an indoor rearing component. Specifically, we compared post-release behaviours of tortoises reared under a combination of indoor and outdoor rearing to tortoises from two other treatment groups - same-aged, but smaller, tortoises reared solely outdoors and similar-sized, but older, tortoises reared solely outdoors. We focused on burrow and cover use, as these behaviours are likely to influence post-release survival. 


\section{ACTION}

\section{Study site}

We reared all tortoises at the Ivanpah Desert Tortoise Research Facility (IDTRF; Lat: 35.4516297, Long: 115.3903042). Both the IDTRF and the tortoise release site were located in the Ivanpah Valley of the Mojave National Preserve (MNP), San Bernardino County, CA, USA. Located $15 \mathrm{~km}$ from the IDTRF, the release site supported high quality desert tortoise habitat dominated by creosote bush (Larrea tridentata), white bursage (Ambrosia dumosa), big galleta (Pleuraphis rigida), littleleaf ratany (Krameria erecta), and heavily intermixed Yucca (Y. schidigera, and Y. brevifolia) and cholla cacti (primarily Cylindropuntia echinocarpa) (Todd et al. 2016).

\section{Obtaining hatchlings}

Hatchlings were obtained from wild females using protocols described in McGovern et al. (2020a). Prior to randomly assigning each hatchling to a husbandry treatment (described below), we marked all hatchlings by notching unique combinations of marginal scutes to enable identification of individuals once released. The present study includes hatchlings from the 2011, 2012 and 2016 cohorts that were released in September 2018 (details below).

\section{Outdoor rearing}

The IDTRF consists of three outdoor predator-proof head-starting enclosures in addition to a female nesting enclosure. Two of the three head-starting enclosures were partitioned into nine rearing pens each $(9 \times 9 \mathrm{~m}$, Figure 1$)$, and the third enclosure was designed to accommodate larger juveniles and consisted of three $9 \times 30 \mathrm{~m}$ 'grow out' pens. Each enclosure was built around natural desert tortoise habitat to which we added rocks, Yucca logs and artificial burrows for shelter. We provided supplemental rain via rotating garden sprinklers every $1-2$ weeks during the tortoise active season (March - October, see Daly et al. 2018, Tuberville et al. 2019). Tortoise density in individual pens was $\leq 10$ individuals per $100 \mathrm{~m}^{2}$. Beginning in September 2015, we provided (at each watering) supplemental food in the form of a mix of leafy greens (dandelion Taraxacum officinale, mustard greens

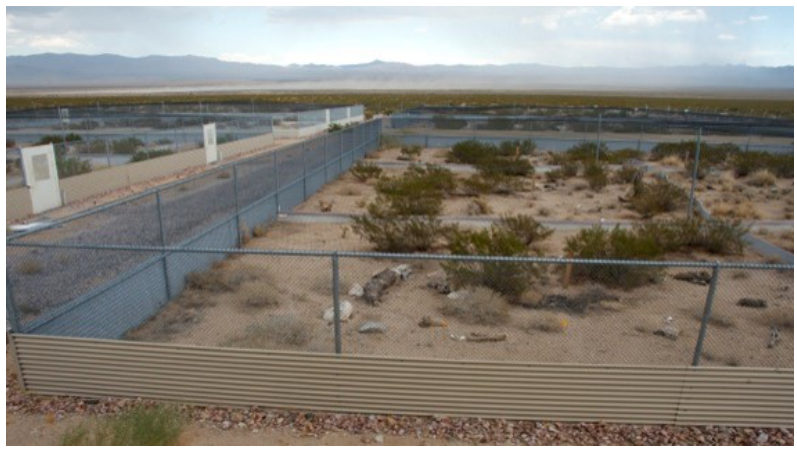

Figure 1. Outdoor rearing pens for Mojave desert tortoises at the Ivanpah Desert Tortoise Research Facility, San Bernardino County, CA, USA.
Brassica juncea, collards $B$. oleracea, turnip greens $B$. rapa, endive Cichorium endivia, escarole $C$. endivia latifolia) and Mazuri ${ }^{\circledR}$ Tortoise Diet 5M21 (Mazuri Exotic Animal Nutrition, St. Louis, MO; see McGovern et al. 2020 b for full details), closely approximating the nutritional properties of the desert tortoise's natural diet (Jarchow et al. 2002).

The captive period of all animals in this study included an outdoor rearing component. The $2011-2012$ Outdoor HS were reared entirely outdoors - initially in the smaller $9 \times 9 \mathrm{~m}$ pens but later in two larger grow out pens $(2015$ until release). The 2016 Outdoor HS animals were reared exclusively in the $9 \times 9 \mathrm{~m}$ pens for two years, whereas the 2016 Combo HS animals spent one year outdoors in a single grow out pen after one year of indoor rearing.

\section{Indoor rearing}

Indoor rearing occurred in the climate controlled IDTRF building, allowing tortoises to forego dormancy and continue feeding and growing year-round (Daly et al. 2018, McGovern et al. 2020b). Tortoises from the 2016 Combo HS group were kept at a maximum density of five tortoises per indoor rearing tub, constructed from 50gallon (189-L) Rubbermaid (Atlanta, Georgia, USA) stock tanks $(132 \times 79 \times 30.5 \mathrm{~cm})$ and filled with $\sim 5 \mathrm{~cm}$ of natural substrate (Figures 2, 3). In each tub, we also included a humid hide box (Rubbermaid Roughneck, Atlanta, Georgia, USA, $40 \times 26 \times 18 \mathrm{~cm}$ ) as a refugium, as well as three hides made from longitudinally halved plastic pipe (11.5 $\mathrm{cm}$ in diameter and $12 \mathrm{~cm}$ in length). Humid hide boxes were filled with $\sim 4 \mathrm{~cm}$ of peat moss, which we moistened every $3-4$ days and replaced every 14 days. While indoors, tortoises did not have the opportunity to dig their own burrows. Each tub was fitted with Mini Combo Deep Dome Dual Lamp Fixtures (ZooMed Laboratories Inc., San Luis Obispo, California, USA), containing both a $50 \mathrm{~W}$ ZooMed Repti Basking Spot Lamp bulb for daytime basking and a ZooMed $50 \mathrm{~W}$ Infrared Basking Spot bulb for night-time heat. For optimal calcium metabolism and Vitamin D3 conversion, we also attached a 26 W Exo-Terra Reptile UVB150 bulb (Rolf C. Hagen Corp., Mansfield, Massachusetts., USA) to each tub (Figures 2, 3).

During their year indoors, 2016 Combo HS animals were fed 4-5 times per week as well as soaked weekly in $1-2 \mathrm{~cm}$ of water for $15-30 \mathrm{~min}$. While the food mixture was the same as described above for the solely outdoor reared cohorts, 2016 Combo HS animals also received a calcium supplement (Rep-Cal Calcium with Vitamin D3, Rep-Cal Research Labs, Los Gatos, California, USA) twice weekly while indoors (September 2016 - September 2017). 


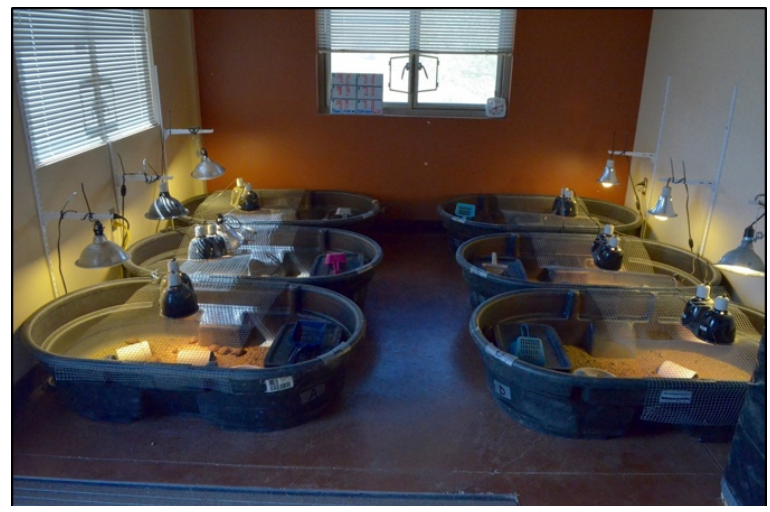

Figure 2. Indoor mesocosms at the Ivanpah Desert Tortoise Research Facility, San Bernardino County, CA, USA, used for indoor rearing of Mojave desert tortoises for their first year.

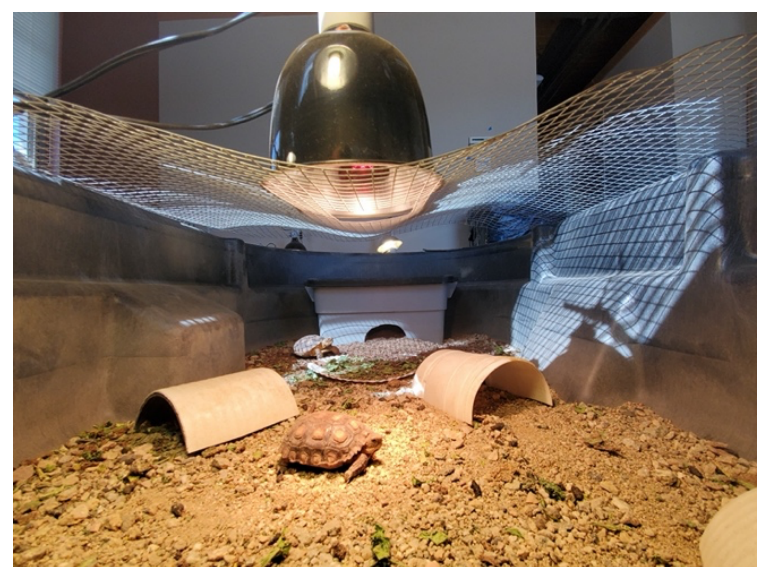

Figure 3. Individual indoor mesocosm at the Ivanpah Desert Tortoise Research Facility, San Bernardino County, CA, USA, showing the interior setup of each of the 6 tubs used in this study, i.e., cover items, substrate, lighting (basking, infrared and UVB), and humid hidebox.

\section{Release}

We released all tortoises $(n=78)$ inside the MNP on 25 September 2018. Tortoises were released in three blocks, approximately $350 \mathrm{~m}$ apart and each containing 26 pre-defined release points. Each release point, approximately $50 \mathrm{~m}$ apart, consisted of an intact kangaroo rat burrow (Dipodomys spp., modified if needed to fit larger tortoises) under a large perennial shrub $(\mathrm{n}=71$ under L. tridentata, $\mathrm{n}=5$ under $C$. echinocarpa and $\mathrm{n}=2$ under $A$. dumosa). We released tortoises into their preselected refugia between 06:00 and 10:00 $\mathrm{h}$ to avoid the warmer part of the day. We soaked and fed all tortoises prior to release.

\section{Post-release monitoring}

Prior to release, we affixed VHF radio-transmitters $(<$ $6 \%$ of the individual's mass) to each tortoise. We attached transmitters (3.1 g R1670 model on 2016 Outdoor HS tortoises, $3.6 \mathrm{~g} \mathrm{R} 1680$ model on all others; Advanced Telemetry Systems, MN, USA) to the fifth vertebral scute using 5-minute epoxy (Devcon 5-minute epoxy gel, ITW
Engineered Polymers, County Clare, Ireland). We monitored tortoises for their first year after release (September 2018 - September 2019).

We tracked all individuals 24 hours after release and then twice per week for the first three weeks post-release. After this initial settlement phase, we reduced tracking to weekly until winter dormancy (31 October 2018). During dormancy (November 2018 - February 2019), we reduced tracking to once every $10-14$ days, before again resuming weekly tracking in March 2019 as animals began to emerge from winter inactivity.

\section{Burrow use}

Burrows are critical resources for desert tortoises, providing refuge from predators and temperature extremes and helping to reduce desiccation; $>90 \%$ of their lives are spent in burrows (Zimmerman et al. 1994). When a tortoise was found in a burrow, we recorded the orientation of the burrow opening and, if under vegetative cover, the plant species providing the cover. Each time an individual was found outside of a burrow but still under vegetative cover, we also identified the species of cover plant. A tortoise was considered inside a burrow if any part of the animal's body was inside the refugium. By marking each separate burrow used by each individual with a labelled wooden stick half-buried near the burrow opening, we were able to record both the number of days before an animal was first found using a burrow and the number of separate burrows used by each individual. These individual values were averaged by treatment in our comparison of the three treatment groups. Holes were described as burrows whether they were dug by the individual, originally dug by another tortoise and then subsequently used by a new individual, or originally dug by a burrowing mammal (e.g., kit fox Vulpes macrotis, kangaroo rats, round-tailed ground squirrel Xerospermophilus tereticaudus).

\section{Dormancy duration}

Because head-started tortoises do not undergo winter dormancy during the indoor-rearing phase, we were interested in post-release winter dormancy behaviour in animals reared with and without an indoor-rearing component. We calculated post-release dormancy duration for each individual by counting the number of days between the date that an individual was first considered dormant (date after the last movement) and the date that same individual was first seen the following spring (emergence date). Given the weekly tracking schedule employed in this study, dormancy duration values have the potential to differ slightly $( \pm 12 \mathrm{~d})$ from the true duration.

\section{Burrow length}

Longer burrows may provide greater protection from digging predators and temperature extremes, particularly during dormancy. Thus, following dormancy, we recorded burrow length $(\mathrm{cm})$ of each individual's dormancy burrow by inserting a pliable plastic pipe $(2 \mathrm{~cm}$ diameter) into each burrow until the end of the pipe came in contact with the back of the burrow. We then marked a line on the pipe using permanent marker, before removing the pipe from 
the burrow to measure the distance from the end of the pipe to the marker line. We only measured dormancy burrow length after confirming that the resident tortoise was found outside the burrow on that tracking occasion.

\section{Vegetative structure and use}

To describe and compare the available plant assemblages used by tortoises, we sampled the perennial plant community at $30(5 \times 5 \mathrm{~m})$ randomly selected plots within the release site. Plots were surveyed between $19-$ 22 May 2019. We counted each individual perennial plant wider than $10 \mathrm{~cm}$ (the approximate mean tortoise size released in this study) and identified each live plant to species. The surveyed plant assemblage was compared to vegetation cover data collected during radio-tracking to determine plant selectivity by tortoises for both burrow placement and use as direct cover when on the surface.

\section{Statistical methods}

We used R (R Core Team 2018) for all statistical tests, with all inferences supported at a threshold type I error rate (alpha) of 0.05 . We present all data as group means \pm 1 standard error (SE). To test model assumptions of normally distributed residuals, we used graphical visualization of model residuals and Shapiro-Wilk tests. We used linear mixed effects models (LME; nlme package 3.1-137, lme function; Pinheiro et al. 2018) to test for differences between treatment groups in MCL at release, the number of unique burrows used in the first-year post release, the time to first burrow use (days), and dormancy duration (days). We used the 'glht' function in package 'multcomp' (1.4-8; Hothorn et al. 2008) to run post-hoc Tukey contrasts when F-tests revealed significant differences among tested groups. When comparing differences in dormancy burrow length amongst released tortoises we substituted cohort $(2011,2012,2016$ a for 2016 Combo HS, 2016b for 2016 Outdoor HS) in place of treatment group. To account for maternal effects, we included mother identity as a random effect in all models.

\section{CONSEQUENCES}

We released tortoises from three different headstarting treatments (described above), which allowed us to compare partially indoor-reared head-started tortoises (2016 Combo HS) to solely outdoor-reared head-started tortoises of either their same age (2016 Outdoor HS) or similar size $(2011-2012$ Outdoor HS $\bar{x}=125.3 \pm 2.2 \mathrm{~mm}$ midline carapace length [MCL] cf. 2016 Combo HS $\bar{x}=$ $117.2 \pm 1.7 \mathrm{~mm}$ MCL, $\mathrm{p}=0.020 ; 2016$ Outdoor HS animals were significantly smaller at release than both other groups, $\overline{\mathrm{x}}=83.7 \pm 1.7 \mathrm{~mm} \mathrm{MCL}, \mathrm{p}<0.001)$. Treatment groups exhibited similar burrowing and dormancy behaviour for all metrics we measured except dormancy burrow length, which differed significantly among treatments $(p=0.001 ; p>0.05$ for all other metrics; Table 1). Treatment groups were similar in time to first burrow use $(\mathrm{p}=0.614$, Table 1$)$, although due to the twice weekly tracking schedule at the onset of this study, the first date of burrow use may not be precise. The 2016 Combo HS animals took 5.5 days (range $=1-18$ ) to establish themselves in a burrow and 2016 Outdoor HS and 2011 2012 Outdoor HS animals took 4.9 days (range $=1-17$ ) and 6.1 days (range $=1-18$ ), respectively. In the first year following release (September 2018 - September 2019), tortoises also used a similar number of unique burrows across all treatment groups (treatment means 6.3 - 7.1; p $=0.548$; Table 1). The 2011 and 2012 Outdoor HS tortoises used significantly longer dormancy burrows than 2016 Outdoor HS animals ( $\leq 0.005)$. Although the 2011 - 2012 Outdoor HS tortoises also used burrows $\sim 10 \mathrm{~cm}$ longer on average than 2016 Combo HS tortoises, the difference was not statistically significant $(p \geq 0.140$; Table 1). The first juvenile tortoise was dormant by 02 October 2018, with all tortoises initiating dormancy by 31 October 2018. The last juvenile had emerged from dormancy by 19 April 2019 after a dormancy duration ranging from 135 - 180 days across all released animals. Average dormancy duration did not vary significantly among treatments $(p=0.078$; Table 1$)$, though the 2016 Combo HS group was dormant for around a week longer than the other treatments.

The release site habitat was structurally heterogeneous, with total perennial counts ranging between 10-47 individual plants per plot. Table 2 shows the abundance of cover plant species used by tortoises recorded at the release site. Other perennials (OTHER, Table 2) recorded were apparently avoided by tortoises for both surface cover and burrow placement. Availability did not mirror the observed usage, with tortoises from all treatment groups using LATR more than any other plant type for both cover while on the surface and as burrow cover (Table 2). CHOL was the second most frequently used cover type for all treatment groups for both cover metrics, except for the 2011-2012 Outdoor HS group, which used PLRI more often than CHOL for cover while on the surface (Table 2). Smaller tortoises (2016 Outdoor HS) used PLRI far less often than the 2011-2012 Outdoor HS animals, though all treatments seemed to avoid making burrows under PLRI (Table 2). YUCCA was also used more often for cover while on the surface than as cover for burrows for all treatment groups (Table 2). 
Table 1. Burrow metrics for 78 head-started Mojave desert tortoises from three treatment groups released in the Mojave National Preserve, San Bernardino County, California, USA based on one year of monitoring using radio-telemetry following their release on 25 September 2018. The three treatments were 2016 cohort animals reared indoors for one year followed by one year of outdoor rearing $(2016$ Combo HS; $n=24), 2016$ cohort animals reared solely outdoors for two years (2016 Outdoor HS; $\mathrm{n}=24$ ), and 2011-2012 cohort animals reared solely outdoors for 6-7 years (2011-2012 Outdoor HS; $n=30$ ). Values are reported as means (ranges in parentheses) for each treatment. The $p$ values are based on linear mixed effect (lme) model results; when lme results were significant (bold), superscripts indicate treatments that significantly differed based on post hoc Tukey's HSD tests.

\begin{tabular}{|c|c|c|c|c|}
\hline Metric & $\begin{array}{l}2016 \\
\text { Combo HS }\end{array}$ & $\begin{array}{l}2016 \\
\text { Outdoor HS }\end{array}$ & $\begin{array}{l}2011-2012 \\
\text { Outdoor HS }\end{array}$ & p value \\
\hline Time to first burrow (days) & $5.5(3.8-7.2)$ & $4.9(3.1-6.7)$ & $6.1(4.5-7.6)$ & 0.614 \\
\hline Mean \# unique burrows & $6.3(5.2-7.4)$ & $6.3(5.1-7.5)$ & $7.1(6.3-8.0)$ & 0.548 \\
\hline Dormancy burrow length $(\mathrm{cm})$ & $50.0(43.1-56.8)^{\mathrm{A}, \mathrm{B}}$ & $40.9(35.2-46.7)^{\mathrm{B}}$ & $60.8(54.3-67.2)^{\mathrm{A}}$ & 0.001 \\
\hline Dormancy duration (days) & $164(158-169)$ & $157(151-162)$ & $156(152-161)$ & 0.078 \\
\hline Dormancy onset (2018) & $\begin{array}{l}\text { 12-Oct. } \\
\text { (10-Oct.-15-Oct.) }\end{array}$ & $\begin{array}{l}\text { 15-Oct. } \\
\text { (13-Oct.-19-Oct.) }\end{array}$ & $\begin{array}{l}\text { 16-Oct. } \\
\text { (13-Oct.-18-Oct.) }\end{array}$ & - \\
\hline Dormancy termination (2019) & $\begin{array}{l}\text { 27-Mar. } \\
\text { (24-Mar.-30-Mar.) }\end{array}$ & $\begin{array}{l}\text { 23-Mar. } \\
\text { (19-Mar.-27-Mar.) }\end{array}$ & $\begin{array}{l}\text { 23-Mar. } \\
\text { (20-Mar.-25-Mar.) }\end{array}$ & - \\
\hline
\end{tabular}

Table 2. Availability versus average use of cover plants by head-started Mojave desert tortoises (Gopherus agassizii) released into the Mojave National Preserve and radio-tracked between 25 September 2018 - 27 September 2019. Availability is based on $30(5 \times 5 \mathrm{~m})$ random sampling plots within the head-start release area ('Representation in random plots'). 'Used for surface cover' represents the percentage of tracking events when that treatment group was found under a specific type of cover plant for all tracking events during which that treatment group was found under plant cover on the surface. 'Used for burrows' represents the percentage of unique burrows located under a specific type of cover plant for all burrows located under vegetative cover. LATR $=$ creosote bush $($ Larrea tridentata $), \mathrm{CHOL}=$ cholla cacti $($ Cylindropuntia sp.), KRER $=$ littleleaf ratany $($ Krameria erecta $), \mathrm{AMDU}=$ white bursage $($ Ambrosia dumosa $), \mathrm{YUCCA}=($ Yucca schidigera $)$, PLRI $=$ big galleta $($ Pleuraphis rigida $)$, OTHER $=$ Anderson boxthorn $($ Lycium andersonii $)+$ Ephedra $($ Ephedra sp. $)+$ bladder sage $($ Scutelaria mexicana $)+$ burrobrush (Hymenoclea salsola) + beavertail cactus (Opuntia basilaris) + cotton top cactus (Echinocactus polycephalus).

Used for surface cover

Used for burrows

\begin{tabular}{llllllllll}
\cline { 3 - 9 } $\begin{array}{l}\text { Cover } \\
\text { type }\end{array}$ & $\begin{array}{l}\text { Representation } \\
\text { in random } \\
\text { plots }\end{array}$ & All & $\begin{array}{l}\text { 2016 } \\
\text { Combo } \\
\text { HS }\end{array}$ & $\begin{array}{l}\mathbf{2 0 1 6} \\
\text { Outdoor } \\
\text { HS }\end{array}$ & $\begin{array}{l}\mathbf{2 0 1 1 -} \\
\mathbf{2 0 1 2} \\
\text { Outdoor } \\
\text { HS }\end{array}$ & All & $\begin{array}{l}\mathbf{2 0 1 6} \\
\text { Combo } \\
\text { HS }\end{array}$ & $\begin{array}{l}\mathbf{2 0 1 6} \\
\text { Outdoor } \\
\text { HS }\end{array}$ & $\begin{array}{l}\mathbf{2 0 1 1 -} \\
\mathbf{2 0 1 2} \\
\text { Outdoor } \\
\text { HS }\end{array}$ \\
\hline LATR & $11.1 \%$ & $42.9 \%$ & $39.9 \%$ & $42.8 \%$ & $45.9 \%$ & $48.3 \%$ & $41.7 \%$ & $49.7 \%$ & $53.9 \%$ \\
CHOL & $3.9 \%$ & $13.7 \%$ & $14.5 \%$ & $15.3 \%$ & $12.0 \%$ & $14.0 \%$ & $15.3 \%$ & $17.2 \%$ & $10.9 \%$ \\
KRER & $8.3 \%$ & $9.8 \%$ & $13.4 \%$ & $10.6 \%$ & $6.1 \%$ & $11.8 \%$ & $15.3 \%$ & $11.0 \%$ & $10.4 \%$ \\
AMDU & $34.5 \%$ & $7.1 \%$ & $7.6 \%$ & $7.2 \%$ & $6.1 \%$ & $7.5 \%$ & $10.4 \%$ & $9.7 \%$ & $5.7 \%$ \\
YUCCA & $1.6 \%$ & $10.7 \%$ & $9.3 \%$ & $13.1 \%$ & $10.2 \%$ & $5.7 \%$ & $4.9 \%$ & $5.5 \%$ & $6.2 \%$ \\
PLRI & $31.8 \%$ & $8.9 \%$ & $6.6 \%$ & $6.7 \%$ & $12.5 \%$ & $5.5 \%$ & $6.3 \%$ & $5.5 \%$ & $6.2 \%$ \\
OTHER & $8.9 \%$ & $6.9 \%$ & $8.7 \%$ & $4.3 \%$ & $7.2 \%$ & $7.3 \%$ & $6.3 \%$ & $1.4 \%$ & $6.7 \%$ \\
\hline
\end{tabular}

\section{DISCUSSION}

Understanding the effects of management interventions is vital in ensuring the most efficient and successful approach to species conservation. Here, we sought to investigate the effects of indoor rearing versus the conventional method of solely outdoor head-starting on post-release cover and burrow use of juvenile Mojave desert tortoises. We found that partially indoor-reared tortoises (2016 Combo HS) exhibited similar post-release behaviours when compared to both same-aged, but smaller (2016 Outdoor HS), and similar-sized, but older outdoorreared head-started tortoises (2011 - 2012 Outdoor HS). All treatment groups selected burrows facing predominantly SSW, corroborating previous findings of juvenile desert tortoise burrow selection (Berry \& Turner 1986). Though burrow length varied with tortoise size, the practice of indoor rearing did not seem to alter any burrow metric measured in this study, perhaps because all treatment groups were exposed to at least one year of 
outdoor rearing prior to release. Tortoises from all treatment groups settled into their first burrow within similar time frames and used nearly an identical number of unique burrows during their first year after release, while spending a similar amount of time inactive during winter dormancy. Likewise, all treatments used the available vegetation cover within the release area similarly, exhibiting selection for certain perennial species to a greater extent than predicted by their relative availability. Indoor rearing did not appear to alter any of the measured post-release behaviours for head-started desert tortoises released into the wild.

If previous findings of the positive relationship between larger size and increased survival for juvenile desert tortoises are confirmed (Nagy et al. 2015b, McGovern et al. 2020a), then the accelerated growth associated with indoor rearing may allow for greater success and efficiency of head-starting, without apparent alteration of burrowing behaviour or cover use following release. While burrowing behaviour and cover use are just two aspects to consider when evaluating head-starting options, it is promising that tortoises reared partially indoors (2016 Combo HS) exhibited similar post-release cover use and burrowing behaviours when compared to conventionally raised outdoor head-starts. Also, partially indoor-reared tortoises were equivalent in size to six-yearold solely outdoor-reared head-starts after just two years of combination head-starting, resulting in four years' worth of saved investment. Though the ultimate success of head-starting programs must be evaluated based on the long-term establishment of a self-sustaining, viable population, the short-term results of this study reveal that indoor rearing warrants further evaluation as a method for increasing the success and decreasing the costs of headstarting the threatened Mojave desert tortoise.

\section{ACKNOWLEDGEMENTS}

We thank Carmen Candal, Collin Richter, Jacob Daly, and Melia Nafus for their assistance with fieldwork and husbandry. Debra Hughson (U.S. National Park Service Mojave National Preserve) facilitated research in the Preserve. Funding was provided by the National Park Service (PSAC-CESU Cooperative Agreement number P17AC01606) and California Energy Commission (Agreement number EPC-16-038). Additional support was provided by the Department of Energy under Award Number DE-EM0004391 to the University of Georgia Research Foundation. All methods followed procedures approved by the University of Georgia Animal Care and Use Committee (number A2017 01-021-Y3-A3) and permits issued by USFWS (number TE-17838A-3), United States National Park Service (number MOJA2011-SCI-0056 [under study MOJA-00258]), and California Department of Fish and Wildlife (number SC0011221).

\section{REFERENCES}

Averill-Murray R.C., Darst C.R., Field K.J. \& Allison L.J. (2012) A new approach to conservation of the Mojave desert tortoise. BioScience, 62, 893-899. https://doi.org/10.1525/bio.2012.62.10.9

Berry K.H. \& Turner F.B. (1986) Spring activities and habits of juvenile desert tortoises, Gopherus agassizii, in California. Copeia, 4, 1010-1012. https://doi.org/10.2307/1445302

Burke R.L. (2015) Head-starting turtles: learning from experience. Herpetological Conservation and Biology, 10, 299-308.

Daly J.A., Buhlmann K.A., Todd B.D., Moore C.T., Peaden J.M. \& Tuberville T.D. (2018) Comparing growth and body condition of indoor-reared, outdoorreared, and direct-released juvenile Mojave desert tortoises. Herpetological Conservation and Biology, 13, 622-633.

Frazer N. B. (1992) Sea turtle conservation and halfway technology. Conservation Biology, 6, 179-184. https://doi.org/10.1046/j.1523-1739.1992.620179.x

Hazard L.C., Morafka D.J. \& Hillard L.S. (2015) Postrelease dispersal and predation of head-started juvenile desert tortoises (Gopherus agassizii): effect of release site distance on homing behavior. Herpetological Conservation and Biology, 10, 504515.

Hothorn T, Bretz F, \& Westfall P. (2008). Simultaneous inference in general parametric models. Biometrical Journal, 50, 346-363. https://doi.org/10.1002/bimj.200810425

Jarchow J.L., Lawler H.E., Van Devender T.R. \& Ivanyi C.S. (2002) Care and diet of captive Sonoran desert tortoises. Pages 289-311 in: T.R. Van Devender (ed.) The Sonoran Desert Tortoise, University of Arizona Press, Tucson, Arizona, USA.

McGovern P.A., Buhlmann K.A., Todd B.D., Moore C.T., Peaden J.M., Hepinstall-Cymerman J., Daly J.A. \& Tuberville T.D. (2020a). The effect of size on post-release survival of head-started Mojave desert tortoises. Journal of Fish and Wildlife Management, 11, 494-506; e1944687X. https://doi.org/10.3996/JFWM-20-014

McGovern P.A., Buhlmann K.A., Todd B.D., Moore C.T., Peaden J.M., Hepinstall-Cymerman J., Daly J.A. \& Tuberville T.D. (2020b). Comparing headstarting techniques for optimal rearing of the Mojave desert tortoise (Gopherus agassizii). Herpetological Conservation and Biology, 15, 626-641.

Nagy K.A., Hillard S., Dickson S. \& Morafka D.J. (2015a) Effects of artificial rain on survivorship, body condition, and growth of head-started desert tortoises (Gopherus agassizii) released to the open desert. Herpetological Conservation and Biology, 10, 535-549. 
Nagy K.A., Hillard L.S., Tuma M.W. \& Morafka D.J. (2015b) Head-started desert tortoises (Gopherus agassizii): movements, survivorship and mortality causes following their release. Herpetological Conservation and Biology, 10, 203-215.

Pinheiro J, Bates D, DebRoy S, Sarkar D, R Core Team. (2018) nlme: Linear and Nonlinear Mixed Effects Models [Internet]. https:/CRAN.Rproject.org/package $=$ nlme

Spencer R.J., Van Dyke J.U. \& Thompson M.B. (2017) Critically evaluating best management practices for preventing freshwater turtle extinctions. Conservation Biology, 31, 1340-1349. https://doi.org/10.1111/cobi.12930

Tetzlaff S.J., Sperry J.H. \& DeGregorio B.A. (2019) Effects of antipredator training, environmental enrichment, and soft release on wildlife translocations: A review and metaanalysis. Biological Conservation, 236, 324-331. https://doi.org/10.1016/j.biocon.2019.05.054
Todd B.D., Halstead B., Chiquoine L.P., Peaden J.M., Buhlmann K.A., Tuberville T.D. \& Nafus M.G. (2016) Habitat selection by juvenile Mojave desert tortoises. The Journal of Wildlife Management, 80, 720-728. https://doi.org/10.1002/jwmg.1054

Tuberville T.D., Buhlmann K.A., Sollmann R., Nafus M.G., Peaden J.M., Daly J.A., Steele M.A. \& Todd B.D. (2019). Effects of short-term outdoor headstarting on growth and survival in the Mojave desert tortoise (Gopherus agassizii). Herpetological Conservation and Biology, 14, 171-184.

Zimmerman L.C., O’Connor M.P., Bulova S.J., Spotila J.R., Kemp S.J., Salice C.J. (1994). Thermal ecology of desert tortoises in the eastern Mojave Desert: seasonal patterns of operative and body temperatures, and microhabitat utilization. Herpetological Monographs, 8, 45-59. https://doi.org/10.2307/1467069

The Conservation Evidence Journal is an open access online journal devoted to publishing the evidence on the effectiveness of management interventions. The other papers from The Conservation Evidence Journal are available from

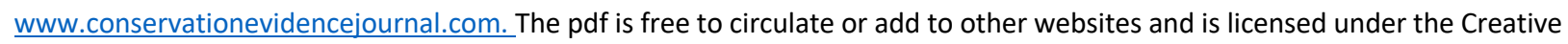
Commons Attribution 4.0 International License http://creativecommons.org/licenses/by/4.0/. Under this licence, authors retain ownership of the copyright for their articles. 